\title{
An integrative analysis of person attributes of e-learning practitioners
}

\section{H. Johannes}

Teaching and Learning with Technology

Tshwane University of Technology

Pretoria, South Africa

e-mail: hermien.johannes@gmail.com

\section{J. G. Knoetze}

Department of Curriculum Studies

University of Pretoria

Pretoria, South Africa

e-mail: jknoetze@mweb.co.za

\section{Ebersohn}

Department of Educational Psychology

University of Pretoria

Pretoria, South Africa

e-mail: liesel.ebersohn@up.ac.za

\begin{abstract}
This article reports on an analysis of person attributes of e-learning practitioners at the Tshwane University of Technology (TUT). Findings from a study of the latent structure of an e-learning practitioner construct, are presented to illuminate the characteristics and personal profiles of the e-learning practitioners at TUT. Rich sources of data, for example interviews, documents and archival records were tapped during the data collection phase. Various data analysis techniques were applied in an integrated manner. Synthesis of these research findings resulted in a number of distinct profiles for the different groups in the TUT population. Apart from the essential personal characteristics identified by the Personal Profile Analysis, the feedback reports from the participants reflected the configuration of relationships of the essential elements in terms of a specific pattern or profile for each respondent. Emerging patterns from the qualitative and quantitative analyses expose the 'what is' and 'what is perceived' as different patterns.
\end{abstract}

\section{INTRODUCTION}

This article reports on an integrative analysis of person attributes of e-learning practitioners at the Tshwane University of Technology (TUT). Work behavioural styles and characteristics of e-learning practitioners in relation to their 
e-learning practice became visible as the e-learning practitioners told their stories through their personal communications, reflective essays, weblogs and their self-reported personal profiles. A full analysis of the work behavioural styles and characteristics of the e-learning practitioners at TUT can be found in the thesis titled: 'In search of the latent structure of an e-learning practitioner construct' (Johannes 2007).

A variety of terms are used relating to the e-learning practitioners, for example 'online teacher', 'e-teacher', 'online professor', 'e-moderator' and 'online facilitator' (Weston and Amundsen 1999; Kemshal-Bell 2001; Backroad Connections 2002; Hoffmann 2003; Illinois Online Network 2003; Salmon 2003), suggest a need for understanding and clarifying the multifaceted nature of the e-learning practitioner. For this article the term 'e-learning practitioner' is an umbrella term referring to practitioners who teach and facilitate in an online environment and who create, use and maintain electronic teaching and learning environments for themselves and their learners for pedagogical purposes. They are involved in a number of job roles, defined by their job description, which suggest a variety of competencies, skills and person attributes needed to fulfil the various job tasks. Special knowledge, competencies and skills needed to perform as an e-learning practitioner are repeatedly stated in the literature (Kemshal-Bell 2001, 13; Salmon 2003, 214; Smith 2005, 5). Assumptions about the usefulness of staff development and training programmes to equip these practitioners are clearly stated in research articles (Ellis, O'Reilly and Debreceny 1998, 191; Kearsley 1998; Stehlik n.d.) and although a change from technological to pedagogical approaches for these programmes is recognised by these programmes, there are certain missing links in this equation.

\section{RATIONALE}

Stated in the literature (Brennan 2003; Salmon 2003), is the importance of the special characteristics needed by e-learning practitioners to successfully practice e-learning, but no evidence of e-learning training programmes accommodating the diversity of e-learning practitioners acting as trainees in terms of their different person attributes could be found. Furthermore, no evidence could be found of screening or assessment procedures applied to identify the personal characteristics of these 'trainees' prior to implementing the training programme. This implies that interventions through elearning training programmes which do not take these very important human aspects into account may, firstly, fail to deliver successfully and, secondly, may lack the flexibility to identify specific niche areas based on personal profiles to accommodate these e-learning practitioners.

The importance of identifying the characteristics and personal profiles of e-learning practitioners relates to two assumptions:

- Firstly, teaching and learning activities based on knowledge about the diversity of person attribute, customised to the preference of individual 'learners', offering 
multimode, individualised learning opportunities, may actively engage e-learning practitioners as 'learners' to a greater extent.

- Secondly, awareness of the personal profiles and characteristics of e-learning practitioners may be beneficial for determining compatibility with job demands and requirements or to guide worker placement in suitable job positions.

The question remains ...

Would we be able to optimise professional development and enhance staff training programmes for e-learning practitioners if the personal profile and characteristics of the e-learning practitioner are known and this knowledge applied to customise these capacity building programmes? Would we be able to give advice, support and guidance to e-learning practitioners on the utilisation of personal strengths in the workplace? Current research on e-learning practitioners suggest some important person attributes in this regard (Kearsley 1998; Gunn 2001; Palloff and Pratt 2001; Brennan 2003; Salmon 2003), but does not provide sufficient answers to these questions and seems to overlook human work style behaviour as an important aspect of the world of work.

We argue in this article that knowledge about the characteristics and how these characteristics fit together in various profiles and person attribute structures may contribute not only to our understanding of the e-learning practitioner construct, but also may be useful in practical applications such as recruitment selection, staff placement or as guidelines for the planning of staff development and training programmes.

\section{CONTEXT}

The focus of this article is e-learning practitioners (see Figure 1:1.1 - A) at TUT, specifically two groups, namely: The Partner group consisting of 14 members (Partners) who follow the Partners@Work (P@W) Programme for 6 months and then practise what they have learned for another 6 months (see Figure 1:1.1 - E), and the e-learning practitioner group (see Figure 1:1.1 - B) including the 'star performer' group. Star performers may be described as e-learning practitioners whose job performance can be rated as an exemplary performance (see Figure 1:1.1 - D). 


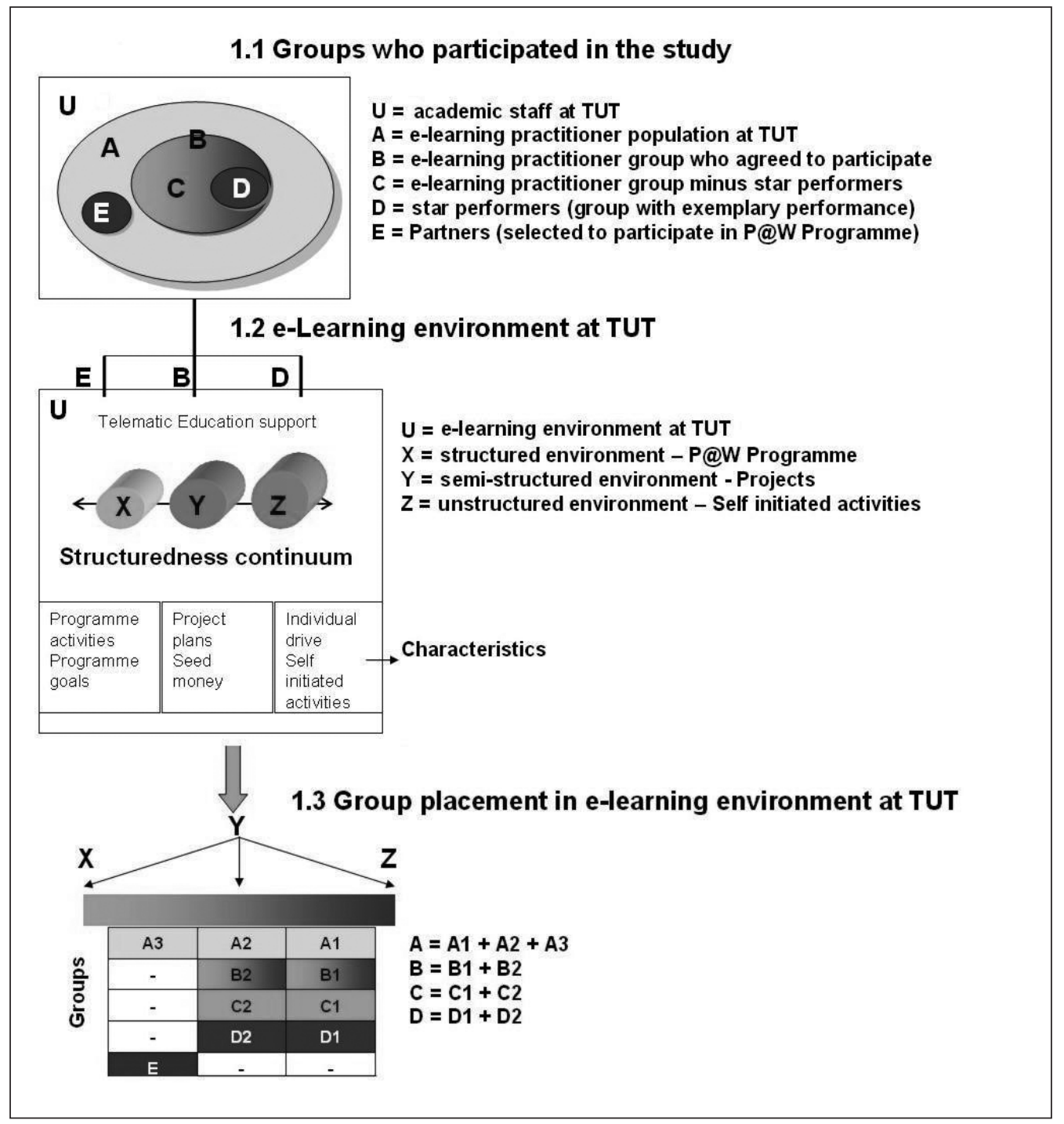

Figure 1: E-Learning context at TUT

These diverse groups represented a variety of e-learning practices such as WebCT courses presented fully online vs. using WebCT as a PDF-file storage manager, the application of different technologies (e.g. e-testing, video conferencing and video supplementary instruction), and the use of a number of approaches (problem-based learning, mastery learning or drill- and practice tutorials). The e-learning group's involvement in e-learning varied from novice practitioners just starting out to experts who have been practising for more than three years. 
All e-learning initiatives at TUT are bounded by organisational policies, rules and regulations, but the carrying out of these activities may take place on a continuum of environmental structuredness. The e-learning environment at TUT consists of unstructured e-learning practices (see Figure 1:1.2-Z), semi-structured e-learning projects (see Figure 1:1.2 - Y) and a structured e-learning programme, the P@W Programme (see Figure 1:1.2 - X). For example, the P@W Programme provides a distinct environmental structure that defines the borders of the programme. Within these P@W Programme parameters definite goals, activities and outcomes for the Partners are set by the programme managers at the Department of Telematic Education. Partners have to adhere to the 'rules' of the programme but do have the intellectual and creative freedom to create their online courses. Semi-structured environments include e-learning practitioners' participation in projects supported by the Department of Telematic Education. Practising in unstructured e-learning environments at TUT involves commitment, driving force and dedication from the practitioners. Their initiative and self-initiated activities are the motivators for their participation in online teaching and learning activities.

\section{THEORETICAL FRAMEWORK}

Bergh and Theron $(2001,510-511)$ are of the opinion that in the work context employees' personality variables form the basis of occupational adjustment. Ongoing adjustment takes place between the employee and the work environment and leads to either congruent or incongruent interactions (Patton and McMahon 1999). If we could understand the operating principles that come into play during these interactions, we might be able to work with them to enhance the matching process and to enhance interaction (Berens 1999). If, however, there is incongruence between the two systems and they are forced to work together, energy is wasted and stress and resistance are triggered (Berens 1999). In this study, the characteristics of e-learning practitioners were analysed to uncover the relevant operating principles.

To gain knowledge about the characteristics of e-learning practitioners in terms of person attributes is a daunting task. However, if the field of attention is narrowed to focus on personal behavioural styles in a work environment as 'operating principles for the system' it becomes more manageable. For this article the DISC model (see Figure 2:2.1) was applied to identify and describe person attributes. 


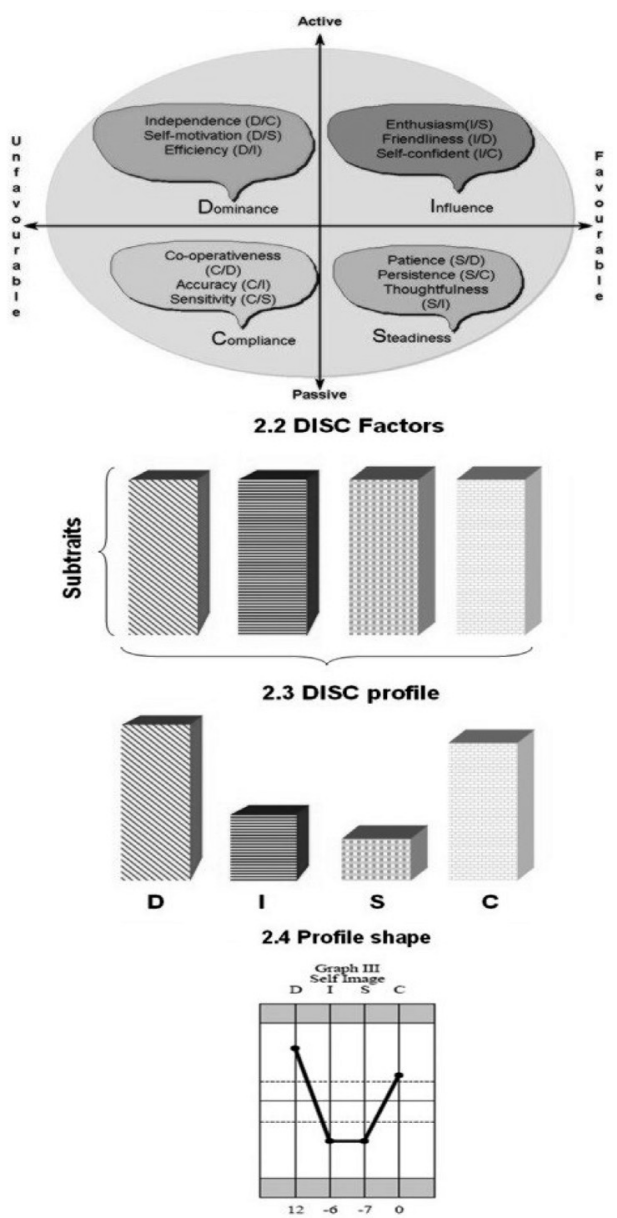

Figure 2: The DISC model

This model focuses on work behavioural styles as embodiments of person characteristics and offers an elegant classification scheme to classify, analyse and relate information pertaining to the characteristics of e-learning practitioners. The DISC model postulates four factors, namely Dominance, Influence, Steadiness and Compliance as typical patterns of interaction of the person in the working environment and can be described by Thomas International, (n.d.) and ManCom Team, (n.d.) as:

- Dominance focuses on POWER and represents how people react to challenges. Keywords describing this factor are inter alia: Driving, competitive, direct and self-starter.

- Influence focuses on PEOPLE and represents how people influence other people to their own viewpoint. Keywords describing this factor are inter alia: Influential, verbal and communicative.

- Steadiness focuses on PACE and represents how people respond to the environmen- 
tal pace. Keywords describing this factor are inter alia: Dependable, good listener, persistent and kind.

- Compliance focuses on POLICY and represents how people respond to rules and procedures set by others. Keywords describing this factor are inter alia: Careful, perfectionist, precise and compliant (list adapted from Thomas International n.d.; ManCom Team n.d.) (see Figure 2:2.1).

The Thomas International Profiling System provides measuring instruments for measuring personal behavioural styles. The latter are described in terms of four DISC factors (see Figure 2:2.2), and different DISC profiles or style types (see Figure 2:2.3) can be displayed as profile shapes (see Figure 2:2.4).

Each DISC profile shows the relevant importance of the four DISC factors in a person's behaviour. These four factors have different properties and subtraits (see Figure 2:2.3) and may lead to more than 1400 variations of analyses (Thomas International n.d.). These combinations facilitate complex interpretations of behaviour style.

The 12 sub-traits, one for each possible pair of factors, enhance understanding of the relationship between factors in a profile (Axiom DISC n.d.). The sub-traits as described by Axiom DISC (n.d.) are listed in Table 1.

Table 1: DISC Sub-traits

\begin{tabular}{|c|c|}
\hline \multicolumn{2}{|l|}{ List of DISC Sub-traits } \\
\hline Sub-trait & Refers to individuals \\
\hline Efficiency (D/I) & Inspired by outcomes \\
\hline Self-motivation (D/S) & Who are 'doers'/'high-flyers' \\
\hline Independence (D/C) & Who follow their own targets \\
\hline Friendliness (I/D) & Who are open and warmhearted \\
\hline Enthusiasm (I/S) & With expressive behaviour \\
\hline Self-confident (I/C) & Who have social confidence and poise \\
\hline Patience (S/D) & Who are 'finisher completers' \\
\hline Thoughtfulness (S/I) & Who think cautiously before they act \\
\hline Persistence $(\mathrm{S} / \mathrm{C})$ & Who show determination \\
\hline Cooperativeness (C/D) & Who prefer to be part of a group \\
\hline Accuracy (C/I, sometimes called Caution) & Focused on correctness \\
\hline Sensitivity (C/S) & Who are perceptive to their surroundings \\
\hline
\end{tabular}

(Adapted from Axiom DISC n.d.)

A person's profile shows a high Steadiness score and a low Influence score (S/I), for example can be interpreted as the person who thinks actions through carefully, and this can be used as a context for interpretation. In this article work behavioural 
styles are expressed in terms of DISC language to describe a particular aspect of work personality structure.

Data capture and analysis of the characteristics of the e-learning practitioner were conducted on two levels, namely the organisational level, including all e-learning practitioners at TUT who agreed to participate (see Figure 1:1.1 - B), and the programme level, including all the Partners in the P@W Programme (see Figure 1:1.1 - E).

\section{RESEARCH METHODOLOGY}

The mixed method approach used in this study, combined the survey and the rapid ethnography methods. The survey method was used to collect quantitative data from the e-learning practitioners about their personal attributes. Rapid ethnography "narrows the focus of field research, employs multiple observation and recording techniques, and also uses collaborative data analysis strategies with other team members' (Irons $2003,12)$. The use of rapid ethnography escalated the research process by using online communication data sources such as discussions and weblogs from the Partner online knowledge building community, to provide rich, complementary data to the quantitative data provided by the Personal Profile Analysis (PPA). The Thomas International PPA is described as 'a validated, non-critical, behavioural analysis that will emphasise a person's strengths and capabilities in the work environment' (Thomas International Resources n.d.).

Data collection instruments included PPA forms, interviews, consent forms, and textual information sets such as essays, weblogs and questionnaires (see Table 2).

Table 2: Data collection instruments

\begin{tabular}{|c|c|c|c|c|c|c|}
\hline $\begin{array}{l}\text { Instrument } \\
\text { (see Figl:1.1) }\end{array}$ & $\begin{array}{l}\text { Survey } \\
\text { PPA }\end{array}$ & Interview & $\begin{array}{l}\text { Rapid virtual } \\
\text { ethnography: } \\
\text { weblogs }\end{array}$ & $\begin{array}{l}\text { Rapid virtual } \\
\text { ethnography: } \\
\text { essays }\end{array}$ & $\begin{array}{l}\text { Consent } \\
\text { forms }\end{array}$ & $\begin{array}{l}\text { Self-reported } \\
\text { feedback: } \\
\text { questionnaire }\end{array}$ \\
\hline B & $v$ & 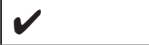 & & & $V$ & \\
\hline$E$ & 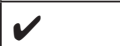 & & $\checkmark$ & $\checkmark$ & 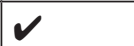 & 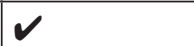 \\
\hline
\end{tabular}

From the total population ( $\mathrm{N}=108) 69$ per cent reacted positively on a call for participation and 56 per cent of the total population completed the PPA forms, the consent forms and the short questionnaire (see Table 3). 
Table 3: Total e-learning population at TUT

\begin{tabular}{|l|l|l|l|}
\hline Composition of TUT e-learning practitioner research group \\
\hline & TUT practitioners & $\begin{array}{l}\text { TUT practitioners ex- } \\
\text { cluding Partners }\end{array}$ & Partners \\
\hline Total population & $\begin{array}{l}108(100 \%) \\
(\text { see Figure 1:1.1 -- A) }\end{array}$ & $94(100 \%)$ & $14(100 \%)$ \\
\hline $\begin{array}{l}\text { React on call for } \\
\text { participation }\end{array}$ & $74(69 \%)$ & $60(64 \%)$ & $14(100 \%)$ \\
\hline Lost interest & $7(6 \%)$ & $7(7.6 \%)$ & $0(0 \%)$ \\
\hline $\begin{array}{l}\text { Promised but did } \\
\text { not deliver }\end{array}$ & $7(6 \%)$ & $7(7.6 \%)$ & $0(0 \%)$ \\
\hline $\begin{array}{l}\text { Completed } \\
\text { Co }\end{array}$ & $(56 \%)$ & $\begin{array}{l}46(49 \%) \\
(\text { see Figure } 1: 1.1--\mathrm{B})\end{array}$ & $\begin{array}{l}14(100 \%) \\
(\text { see Figure } 1: 1.1--\end{array}$ \\
\hline Invalid forms & $2(2 \%)$ & $2(2 \%)$ & $1(7 \%)$ \\
\hline
\end{tabular}

\section{INTEGRATIVE DATA ANALYSIS OF PERSON ATTRIBUTES OF E- LEARNING PRACTITIONERS}

The findings on the person attributes of e-learning practitioners at TUT are based on the quantitative and qualitative data analyses of the PPA reports, textual data and self reported feedback from the participants (see Table 2).

Findings from the quantitative data analysis

The characteristics captured by the PPAs of e-learning practitioners at TUT are listed as being precise, logical, accurate, thorough, careful, systematic, amiable, dependable, independent, assertive, detailed and persistent (see Table 4 -iii). Although there is a marked similarity between this group and the Partners, the latter also shows prominent features of independence, sincerity and scepticism (see Table 4 -ii). Descriptive words which are unique to the Partner group refer to them as being calm, decisive, fair, firm, investigative, non-antagonistic, objective, opinionated, self-confident, suspicious, sympathetic, verbally influential and versatile.

On the other hand, the descriptions of the star performers show uniqueness in being tense, participative, impatient, aloof, self-critical, self-assured, non-trusting, introspective, enforcing and demanding. Furthermore, they are mostly characterised as being active, direct, independent, mobile, precise, dependable, factual, logical, reflective, reserved, self-starters and systematic (see Table 4 -iv).

The results from the PPA reports only partly reflects the current thinking in the literature on e-learning practitioners. Palloff and Pratt (2001) are of the opinion that introverted online teachers are more successful than those with charismatic personalities which does not correspond with the TUT choices of 'peoples person' as being important. An interesting observation is that the list of e-learning practitioner skills 
and characteristics compiled by teachers who participated in the NCVER project 'One size doesn't fit all: Pedagogy in the online environment' reported by Brennan (2003, 48), correlate partly with the profiles of the TUT star performers.

\section{Findings from qualitative data analysis}

By combining and adding the feedback on the characteristics of the e-learning practitioner from the different participative groups, a list of enrichment elements were identified (see Table $4-$ i). The most important characteristics of the e-learning practitioner as perceived by the group of participants in order of descending frequency were creativity, patience, innovativeness/ new ideas, people's person, organised, perseverance, knowledge, effective communication, dedication, skills, enthusiasm, persistence and compassion (see Table $4-\mathrm{i}$ ). Characteristics mentioned as important by the TUT group, and not by the Partner group, were time, supportive, 'clarity of thought', detail orientated, hard working, listening skills and independence.

Characteristics selected by the Partner group that were not chosen by the TUT group were a high frequency of 'people's person', keep up with change, calmness, ambitious, critical (to a certain extent), multitasking and inquisitiveness. The first three, namely 'people's person', keep up with change and calmness were frequently mentioned, and the rest were mentioned at a low frequency.

Translating the selected characteristics into DISC language it is fair to say that this profile points to a person who has a high Dominance/low Compliance factor (creativity, innovativeness, perseverance) combined with a high Compliance and high Influence factor (organised, knowledge, skills, 'peoples person' and effective communication). This means that low and high Compliance factor elements are incorporated and will therefore be a moderate high in this profile. Although patience (high Steadiness) is mentioned frequently, the meaning of the word might be interpreted in the words of one of the Partners as, 'a very important trait is also that the practitioner should have patience not only with regards to the students but with regards to the e-learning system that could be frustrating at times', rather than patience in the sense of work pace.

Feedback on the characteristics of an e-learning practitioner from the TUT groups (see Figure 1:1.1 - B and E), revealed the following:

The e-learning practitioner is a person who is a creative, energetic and driven, who experiments with new technologies, is open-minded, and open to new ideas, innovations and technologies, has compassion for people - students and colleagues alike. He or she loves to communicate and motivate people by influencing them. Can react to challenges and changes in the environment, is organised, goal-orientated and persevering. Has a thorough knowledge of his/her field of specialty and has the ability to function in a team, but also as leader/driver of the students (see Table $4-\mathrm{i}$ ).

From the PPA descriptive words such as independence and accuracy showed the highest frequency in the Partner group (see Table 4 - ii), whilst the combination of independent activity, mobility and directness characterised the star performers. The most important descriptive characteristics of the e-learning practitioners at TUT showed them as logical, precise and accurate individuals (see Table $4-\mathrm{v}$ ). 


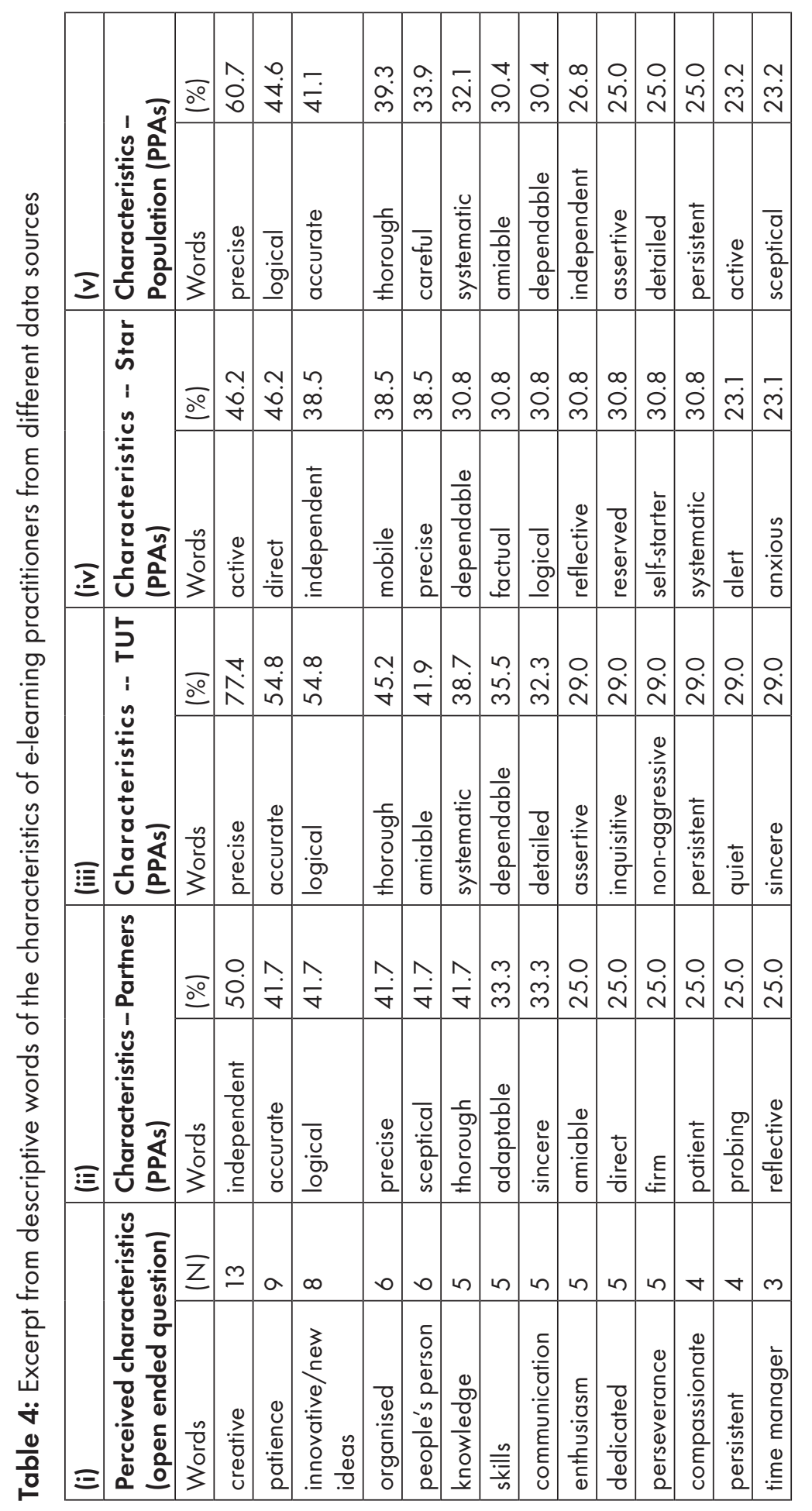


Findings on e-Learning practitioner profiles in terms of DISC factors

However, the results from this study are more complex than suggested by the lists of characteristics mentioned. The PPA of the e-learning practitioners at TUT, aimed not only at identifying the personal characteristics of e-learning practitioners, but also at reporting on comprehensive work behavioural style profiles. The researchers analysed these personal profiles in terms of patterns, relationships and structure to deepen understanding of the construct under investigation. Analysis revealed that the DISC factor distribution for the e-learning practitioners was divided equally between the Influence and Steadiness factors with a frequency of 21 per cent each, the lowest frequency in the Dominance (16\%) and the highest, namely 42 per cent, in the Compliance factor (see Figure $3-\mathrm{A}$ ).

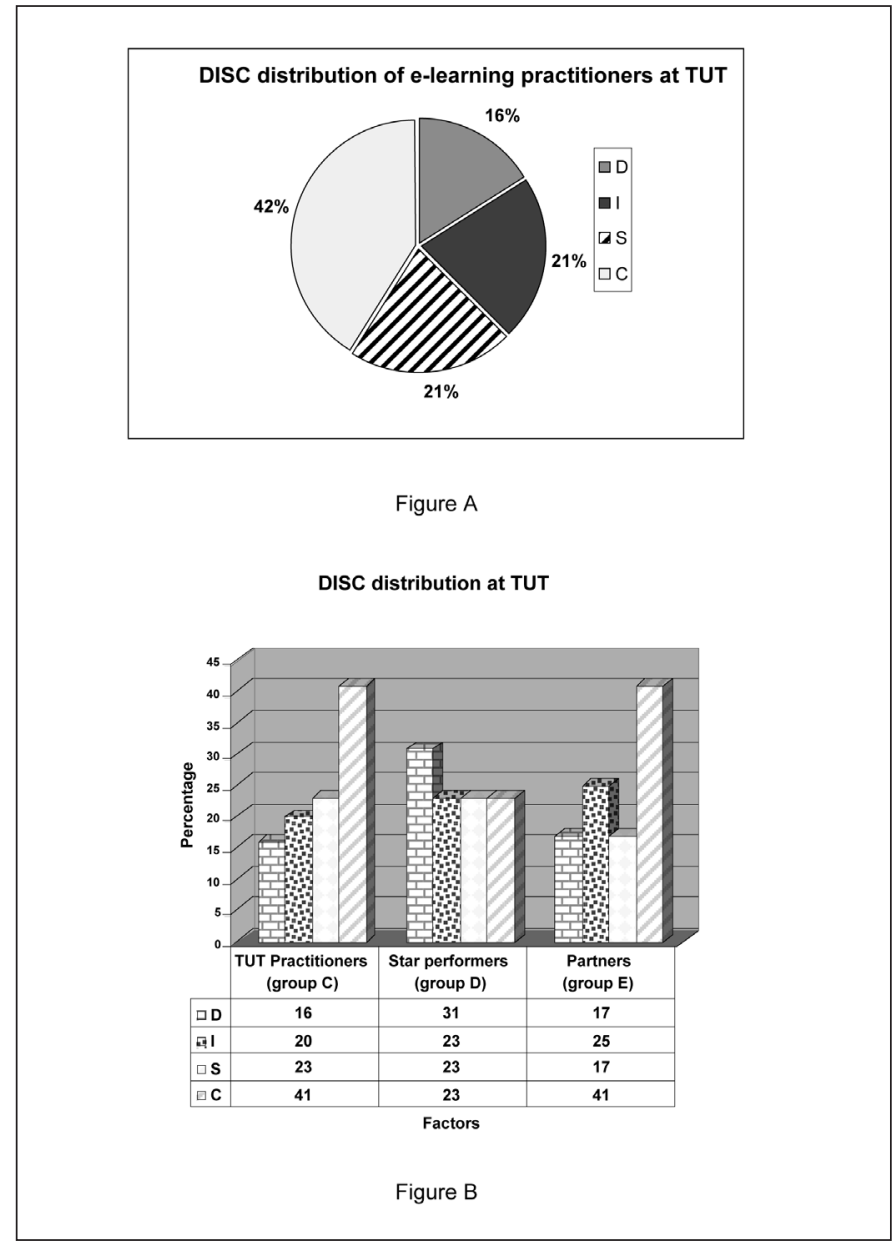

Figure 3: DISC distribution of the e-learning practitioners at TUT 
Therefore it does make sense that characteristics such as logical, precise and accurate, typical of persons with a high Compliance behavioural style will be the most prominent descriptive words for the e-learning practitioners at TUT. An exception is the behavioural styles of the star performer group which were the most prominent in the Dominance factor and evenly distributed in the other factors. This accounts for the star performers being typically described as independent active, mobile and direct.

Based on the previous discussion the basic structure of the e-learning practitioner construct in terms of person attributes as presented by the e-learning practitioners at TUT can be described as consisting of a Compliance-Steadiness-Influence-Dominance configuration (see Figure $3-\mathrm{B}$ ). It is evident from these findings that there is a discrepancy between the perceived importance of behavioural styles within the Dominance factor, and the reality of existing TUT e-learning practitioners' high Compliance style combinations. Judging from evidence produced by the star performer group, it may well be most important to have a high Dominance DISC structure configuration for e-learning practitioners.

\section{The Personal Profile Structure distribution at TUT}

Comparison of the personal profile structure distribution at TUT revealed that each DISC factor displayed a variety of style combinations with clusters in the high Steadiness Compliance (SC), the high Compliance Steadiness (CS), high Compliance Dominance (CD) and the high Influence Dominance (ID) factors (see Figure 4).

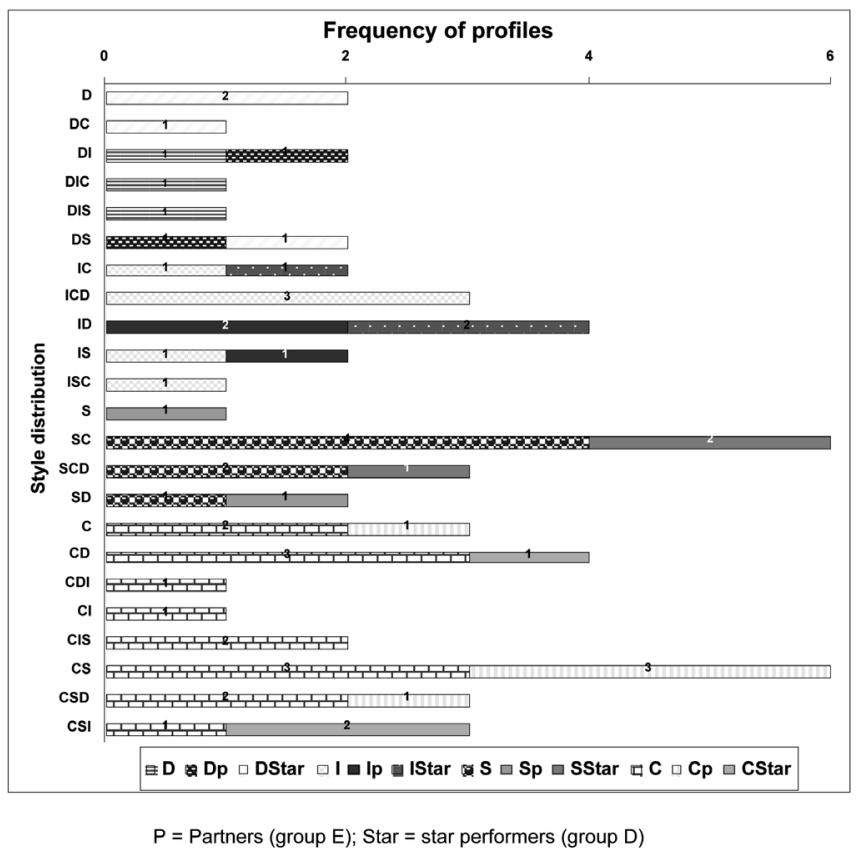

Figure 4: Comparison of the personal profile structure distribution in the TUT, Partner and star performer groups 500 
Comparing the different e-learning practitioner groups to the personal profile patterns revealed very interesting distribution patterns. Using Figure 5 as reference it is clear that there are definite clusters of the high factor style combinations for the different groups. The Partner group (see Figure 1:1.1 - E) displayed a high cluster in the CS style, whilst the star performer group (see Figure 1:1.1 - D) displayed a high cluster in the D style. The TUT group (see Figure 1:1.1 - C) did not display a pertinent high cluster group.

\section{Cluster of "HIGH" factor style combinations}

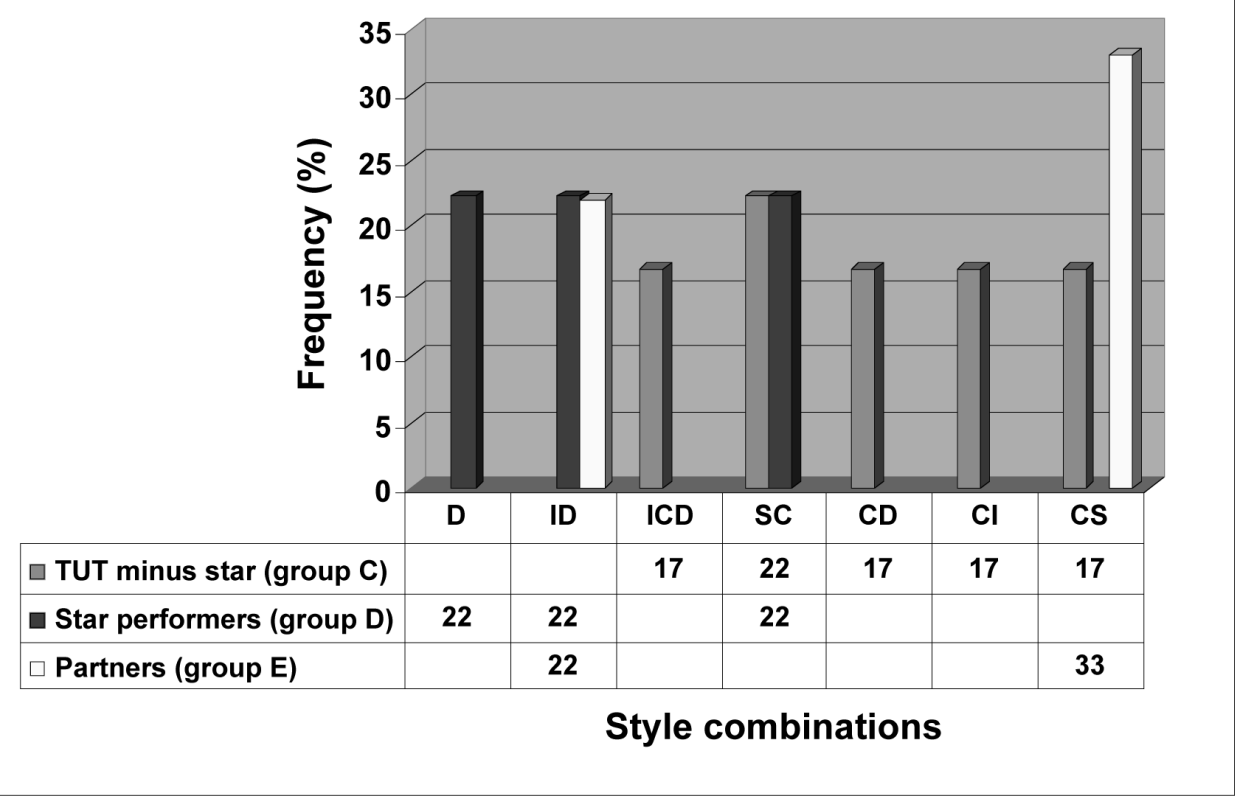

Figure 5: Comparison of clusters of "HIGH" factor style combinations in the TUT, Partner and star performer groups

The significance of these findings will be evident from the practical recommendations in the following paragraphs.

\section{High Dominance and high Influence factors}

Persons presenting behavioural styles with high Dominance and high Influence factors generally prefer an unstructured work environment (see Figure 1:1.3-Z) with freedom to act independently. It is evident from findings in this study that the star performer group (see Figure 1:1.3 - D) has a prominent presence in these factors, whilst the weight of the TUT group (see Figure 1:1.3 - C) is more towards the Compliance and Steadiness factors. This implies that there will be a general tendency for these persons to prefer a more structured work environment (see Figure 1:1.3 - X and $\mathrm{Y}$ ). 
The question may arise as to why the star performer group is different, and the answer may lie in the current organisational context at TUT. At TUT the job of the e-learning practitioner is not defined nor is there a formal job description to guide us in our search for clarification in this matter. However, during the past six years the unstructured e-learning environment at TUT moved on the structuredness continuum (see Figure 1:1.2) to include semi-structured- and structured environments. e-Learning practitioners who were interested in multimode teaching and learning have participated in Telematic Education projects on a voluntarily basis. Support took various forms such as seed money to finance projects, personal support from the staff of Telematic Education, infrastructure for production of teaching and learning materials, and a variety of available technologies. The organisational environment was unstructured and the onus for choices about which roles to play, approaches to follow and applications to use was on the individual practitioner. Furthermore, a vast number of problems and challenges were presented by the lack of implementation infrastructure, large student groups, time constraints, and fellow colleagues who were sometimes very sceptical and unsupportive. In such an environment the individual who is active and energetic, competitive, concerned about results, has the drive to reach set goals, and a passion for solving problems and addressing challenges is more likely to succeed and to survive. These characteristics fit the star performer group who can be described as independent self-starters, who want to 'get on with the job'.

\section{High Steadiness and high Compliance factors}

In contrast to the high Dominance and high Influence group, the group profiling in the high Steadiness and high Compliance factors shows a preference for well-structured environments where logic and accuracy are most important. They have a need for a slower pace and variety as routine and repetitive work may frustrate them. They are persistent, hard-working individuals who investigate facts and may follow a perfectionist approach where systems, procedures, policies and rules are concerned. These characteristics fit three star performers. The Partners (see Figure 1:1.3 - E) in this group prefer a structured work environment (provided by the P@W Programme), with definite guidelines for conducting practice. A number of practitioners in the high SC and CS groups found structure in the personalised support that they received from the instructional designers of the department of Telematic Education. The high steadiness factor group in particular are concerned about relationships, are good listeners, and 'finisher completers' who maintain good relationships with their instructional designers. These practitioners feel reassured by appreciation, hard work, challenge, and recognition for long service.

\section{SUMMARY}

Emerging patterns from the quantitative and qualitative analyses discussed in this article, expose the 'what is' and 'what is perceived' as different patterns. It is 
evident from the preceding paragraphs that the majority of personal profile patterns of the e-learning practitioners at TUT were concentrated in the Compliance factor around three clusters showing CD, CS and CSI style combinations, a further cluster of SC profiles was found in the Steadiness factor. The lowest frequency of profiles was displayed in the Dominance factor. Comparing these patterns with the profiles of the star performers revealed a new, unique pattern for the star performers, namely a cluster in the Dominance factor. Perceptions from the e-learning practitioners revealed yet another pattern, namely a high Dominance factor with creativity and innovativeness as the most important characteristics of the e-learning practitioner. Creativity/innovativeness/originality/unconventionality are briefly mentioned in only three of the PPA reports, not a general characteristic at all! It is also interesting to note that all three of these PPA reports were from star performers. Innovativeness was only once mentioned in the PPA reports from the Partners.

It is fair to argue that the perceptions of the TUT and Partner groups pertaining to the characteristics of the e-learning practitioner are more relevant to the star performers than to the existing e-learning practitioner group at TUT. The existing personal profiles of the e-learning practitioners at TUT differ from these of the star performers and furthermore do not display the most important personal characteristic as perceived by the practitioners themselves.

However, practical interventions discussed elsewhere may act as positive influences to change the practice environment in such a way that all practitioners may find their special niche area in the e-learning environment.

\section{RECOMMENDATIONS FOR FURTHER RESEARCH}

The e-learning practitioner, practicing in the rich, fast moving e-learning context provided scope for a number of exciting research possibilities. Listed below are a few potential research topics:

- in this study, PPA measured work behavioural style. Replication of this study using a different set of lenses, for example the Myers Briggs Inventory and the Work Profiling System as measuring instruments, or application on a more comprehensive scale including participants from a variety of e-learning environments, may reveal more building blocks and patterns in the profile of the e-learning practitioner and could also confirm and verify the findings of this case study.

- unique combinations of characteristics and personal profiles were displayed by the star performer group, and these findings need verification by means of replication at other higher education institutions.

- exploration of (a) the dynamic interaction between e-learning team members with diverse work behavioural styles and (b) the characteristics of e-learning work teams may provide useful pointers to guide the composition of effective e-learning work teams. 


\section{REFERENCES}

Axiom DISC. n.d. DISC History. Available at: http://www.axiomsoftware.com/disc/ history.asp.

Axiom. n.d. Axiomsoftware. Available at: http://www.axiomsoftware.com.

Backroad Connections. 2002. Effective online facilitation. Australian Flexible Learning Framework Quick Guides series, Australian National Training Authority. Available at: http://pre2005.flexiblelearning.net.au/guides/facilitation.html.

Berens, L.V. 1999. The 16 personality types: the self of the self-organizing system. Telos Publications. Available at: http://www.16types.com/Request.jsp?lView=ViewArticle \&Article $=$ OID $\% 3$ A59647.

Bergh, Z. C. and A. L. Theron. 2001. Psychology in the work context. Cape Town: Oxford University Press.

Brennan, R. 2003. One size doesn't fit all. Volume 2. Australian Flexible Learning Framework. Available at: http://www.ncver.edu.au/publications/958.html.

Ellis, A., M. O'Reilly and R. Debreceny. 1998. Staff development responses to the demand for online teaching and learning. Available at: http://www.ascilite.org.au/conferences/ wollongong98/ asc98-pdf/ellis0005.pdf.

Gunn, C. 2001. Effective online teaching: How far do the frameworks go? Ascilite 2001 Conference proceedings, 235-244. Available at: https://secure.ascilite.org.au/ conferences/melbourne01/pdf/papers/gunnc.pdf .

Hoffmann, J. 2003. Be an active and participative instructor. ASTD Learning Circuits. Available at: http://www.learningcicuits.org/2003/dec2003/hofmann.html.

Illinois Online Network. 2003. What makes a successful online facilitator? Illinois Online Network. Available at: http://www.ion.uillinois.edu/resources/tutorials/pedagogy/ instructorProfile.asp.

Irons, L. R. 2003. Rapid ethnography for user experience design. IC Technologies, LLC. Available at: http://www.ic-t.com/publications/UEDesign.pdf .

Johannes, H. 2007. In search of the latent structure of an e-learning practitioner construct. Ph.D. thesis, University of Pretoria. Available at: http://upetd.up.ac.za/thesis/available/ etd-06192007-132241/.

Kearsley, G. 1998. A guide to online education. Available at: http://home.sprynet. com/ gkearsley.

Kemshal-Bell, G. 2001. The online teacher. Final report prepared for the Project Steering Committee of the VET Researchers and Online Learning Project. ITAM ESD, TAFENSW. Available at: http://cyberteacher.onestop.net/final\%20report.pdf .

ManCom Team. n.d. Available at: http://www.mancom/discad.html

Palloff, R. M. and K. Pratt. 2001. Lessons from the cyberspace classroom: the realities of online teaching. San Francisco: Jossey-Bass, Wiley.

Patton, W. and M. McMahon. 1999. Career development and systems theory. A new relationship. Canada: Brooks/Cole

Qualidata. 2003. Available at: http://www.esds.ac.uk/qualidata/about/. 
Salmon, G. 2003. E-moderating: the key to teaching and learning online. (2nd Edition.). London: Routledge Falmer.

Smith, T. C. 2005. Fifty-one competencies for online instruction. Journal of Educators Online 2(2).

Stehlik, T. n.d. Professional development in online learning and flexible delivery in the VET sector - issues for assessment and evaluation. Available at: http://www.unisa. edu.au/evaluations/Full-papers/StehlikFull.doc.

Thomas International. n.d. Available at: http://www.thomasint.cn/Theory.asp and http:// www.thomasint.cn/ent02a.asp.

Thomas International Resources. n.d. Resources provided by Thomas International Registered Analyst.

Weston, C. and C. Amundsen. 1999. Characteristics of effective online instruction. Available at: http://socserv2.mcmater.ca/srnet/3F_weston.htm. 